\title{
Establishing a Three-Dimension Model of Metadiscourse Taxonomy Based on Global Virtual Team's Internal Communication
}

\author{
Siwei Yue \\ School of English for International Business, Guangdong University of Foreign Studies, Guangzhou, China \\ Email: yue111_2000@126.com
}

How to cite this paper: Yue, S. W. (2020). Establishing a Three-Dimension Model of Metadiscourse Taxonomy Based on Global Virtual Team's Internal Communication. Open Journal of Social Sciences, 8, 400-416. https://doi.org/10.4236/jss.2020.812032

Received: November 18, 2020

Accepted: December 27, 2020

Published: December 30, 2020

Copyright $\odot 2020$ by author(s) and Scientific Research Publishing Inc. This work is licensed under the Creative Commons Attribution International License (CC BY 4.0).

http://creativecommons.org/licenses/by/4.0/ (c) (i) Open Access

\begin{abstract}
As COVID-19 epidemic is rampant over the globe, a large amount of enterprises turn to the virtual team to sustain business operations. Among them, international enterprises' business communication and management rely on global virtual teams (GVT) whose members are in different time zones and locations, with different nationalities, cultures and languages, who communicate, manage and operate through the Internet. Based on video conferences of a multinational IT company's GVT, this study explores how GVT members use metadiscourse strategies to bridge cultural differences, business English as lingua franca (BELF) proficiency gap and unstable internet traffic to achieve effective communication. The findings suggest that 1) metadiscourse use of GVT can be divided into three dimensions: relational metadiscourse, textual metadiscourse and BELF-facilitating metadiscourse; 2) to bridge cultural differences, relational metadiscourses that realize the function of "negotiating status distance" and "clarifying speaker's standpoint" help moderate divide in cultural perceptions towards power distance and face management; 3) to cope with BELF proficiency gap, BELF-facilitating metadiscourses of "repetition", "self repair" and "co-construction of meaning" are the most commonly used and realize the function of enhancing intelligibility of BELF speakers' utterance; 4) in response to the Internet-mediated communication barriers, textual metadiscourses of "turn-manipulator" manipulate the number and length of speech turn to ensure the coherence and accuracy of information transmission.
\end{abstract}

\section{Keywords}

Global Virtual Team, Metadiscourse Taxonomy, Business Communication 


\section{Introduction}

As COVID-19 epidemic is rampant over the globe, a large amount of companies turn to virtual teams to sustain business operations. Among them, many MNCS adopt Global Virtual Teams (GVTs) to enable their employees from different countries and cultures to collaborate virtually at a distance to execute team projects. As the increasingly dominant organizational structure in many MNCs, Global Virtual Team refers to a team whose members are separated by time and space, and (more importantly) differ in national, cultural, and linguistic attributes, and whose functioning is heavily dependent on CMC (Zakaria, 2017). Each individual on a multinational team is inherently influenced by his cultural practices and norms, business English as lingua franca (BELF)'s proficiency, and his communicative performance is moderated by CMC resources. Such diversity of mentality and uneven attributes can add to a project's worth (Barinaga, 2007), but it is also an obstacle to the team because it makes them hard to build trust and have to acclimate to differences in communication styles (Nurmi, 2011). Despite increasing studies on GVT's management practices and issues (e.g., decision making process, negotiation styles, leadership roles and characteristics, communication patterns, and trust), there is a dearth of research addressing the GVT's discursive strategies in enhancing its efficacy of internal communication under the contextual influences of intercultural communication, use of BELF and virtual environment.

Metadiscourse is an important language resource that endows the superficial language form with interpersonal functions (Crismore \& Farnsworth, 1990; Hyland, 2005). It plays a pivotal role not only in the textual organization but also in negotiating interpersonal relationship of the communicators. A tactful employment of metadiscourse in GVT internal communication can effectively improve the accuracy of GVT information transmission and establish the trust relationship among members. This study aims to examine the representation and pragmatic functions of metadiscourse in GVT business communication, and to explore how GVT members use metadiscourse strategies to bridge cultural differences, business English as lingua franca (BELF) proficiency differences and internet distance communication barriers to achieve effective communication.

\section{Conceptual Framework}

\subsection{Three Dimensions of Contexts of GVT Internal Communication}

GVTs require company employees to work: 1) with people of varying levels of a common language (i.e., the language of the business interactions), 2) without physical contact among team members, and 3) at all hours of the 24-hour clock, including weekend days or nights depending on work schedules and times in other countries (e.g., Sunday is a workday in Israel and Monday in Australia is Sunday in the United States) (Glazer, Kożusznik, \& Shargo, 2012). It brings three unique interwoven dimensions of contexts in GVT internal communication: 
cultural context (members of different nationalities have different cultural backgrounds), linguistic context (use BELF as the common communication language), and spatial context (dispersed location contributes to a virtual communication mediated by internet). The integration of three dimensions of contexts helps shapes distinctive property of GVT internal communication.

\subsubsection{Cultural Context}

Communication is a process of encoding and decoding messages in ways that fit the communicator's cultural norms, beliefs, values, and rules (Gudykunst, Matsumoto et al., 1996). In order to effectively communicate, a person must be familiar with a culture's norms, beliefs, values, and rules so as to avoid miscommunications (Fujimoto, Bahfen, Fermelis, \& Härtel, 2007; Li, 1999; Triandis, 1994). The diversity of GVT members' culture can vitalize work performance but it can also be ineffective if they can't synergize in terms of cultural practices and norms related to work ethics and practices (Nurmi, 2011). In GVT internal communication, how team members negotiate the relationship between individuals and the team is affected by the cultural synergy of collectivism vs. individualism (Hofsted, 1980) whereas how they manage the relationship between the team leader and team members, meeting hosts and participants, the most influential stakeholders and other stakeholders attributes to the cultural synergy of high power distance vs. low power distance (Hofsted, 1980). As to dealing with conflicts of opinion, team members' stand on either task-driven culture or relationship-driven culture (Hall, 1976) respectively leads to the inclination to confront with conflicts or avoid them. In terms of the communicative styles of GVT internal communication, whether team members resort to explicit or implicit utterances pertains to their adoption of low context or high-context culture (Hall, 1976).

\subsubsection{Linguistic Context}

Provided that members of GVTs must contend with time zone differences; communications that are not clear and concise could cause teams to be days behind their work schedules, regular and concise communication that conveys precise information is very important in GVTs (Uflacker \& Zeier, 2011). Nevertheless, GVT members who speak different mother tongues have to speak BELF-the language used by internationally operating business professionals to communicate with other (mostly) non-native speakers (Kankaanranta \& Louhiala-Salminen, 2013). As foreign language barriers might play a role in creating pitfalls for GVTs, the uneven proficiency of BELF becomes an unescapable challenge for GTV communication, which exerts major impacts on communication manner, content and lexicogrammatical representation. García and Cañado (2011)'s study found significant differences between people with high BELF proficiency and with low BELF proficiency in terms of frequency of turn-taking, interruption and interposing, and the willingness to communicate with native and non-native English speakers. In addition to communication manner, BELF pro- 
ficiency's influence on content is reflected by information density, accuracy and coherence of utterance. The uneven BELF proficiency affects the correct use of vocabulary and grammatical rules (Tenzer et al., 2014) at the lexicogrammatical representation. As a pillar of contextual factors, BELF proficiency is determinant in GVT members' comprehension and exchange of information.

\subsubsection{Spatial Context}

GVT business communication mainly relies on e-mail, video conference and other remote communication means. Limited by the untouchable virtual setting and the busy traffic load of IT communication, even video conference cannot display paralanguage information (gesture, expression, posture, etc.) of physical behaviors which traditional face-to-face team members rely upon to establish and sustain trust. Virtual team members are reliant upon different behaviors, unique to virtual settings, to assess trustworthiness and compensate for the lack of physically observed behaviors (Alsharo, Gregg, \& Ramirez, 2017). Linguistic resource is the dominant clues for them to interpret the message exchanged and the most reliable means to negotiate interpersonal relationship. Spatial context affects the frequency of talks, the way in which team members communicate and the content they communicate. Prior research found that, in virtual team communication, the virtual team via the communications link can hardly share extra talk beside work talk and where facilities were shared, technology controllers dominated cross-site talk (Anderson, McEwan, Bal, \& Carletta, 2007). Compared with face-to-face meeting, the duration of GVT meeting is shortened and the time of each turn is prolonged. The cohesive devices used for turn-taking adopt a more formal style, and the speaker provides more information in each turn (o'conail, Whittaker, \& Wilbur, 1993). Some other research also discovered that members' talk in GVT meeting attaches greater importance to problem-solving (O'conail et al., 1993; Tang \& Isaacs, 1993; Tang, Isaacs, \& Rua, 1994), team members spent more time clarifying their contributions to the meeting (Olson, Olson, \& Meader, 1995; Doherty Sneddon et al., 1997).

\subsection{Metadiscourse Taxonomy of GVT Internal Communication}

Traditionally, metadiscourse is defined as the commentary on a text made by its producer (Hyland \& Jiang, 2018) and recognised as an important means of facilitating communication, supporting a writer's position, and building a relationship with an audience (Hyland, 2004). Over the past few decades, the importance of metadiscourse has been recognized in a few spoken registers (Guillem, 2009; Luke \& Gordon, 2016; Buttny, 2010). It's notable that given that participants of ordinary conversations know each other well, intersubjective cooperation and understanding are often taken for granted and thus it's not prominent to use metadiscourse markers to explicitly highlight interaction, demand collaboration or present discourse (Zhang et al., 2017). In contrast, GVT internal communication underpinned by the contexts of intercultural communication, BELF as working language and virtual environment is mainly dependant on 
tactful employment of metadiscourse to manage the organization of utterance so as to improve the accuracy of information exchanged and to project the communicator's perspective, attitudes and actions to manage social relationships (Hyland \& Jiang, 2018). To address unique characteristics of GVT's three dimensions of contexts, this paper proposes to classify and investigate the metadiscourse used in GVT business communication from three dimensions: relational metadiscourse, textual metadiscourse and BELF-facilitating metadiscourse. Under textual metadiscourse category, this research inherits Hyland (2005)'s metadiscourse classification of interactive resources and enriches the metadiscourse classification framework by proposing relational metadiscourse category and BELF-facilitating metadiscourse category, which targets at the information exchange and interpersonal relationship management of GVT's intercultural, virtual communication in BELF.

\subsubsection{Relational Metadiscourse}

Due to the virtual attributes, there was less intensive communication and interaction in virtual teams (Blackburn et al., 2003). The scarcity of frequent and intensive interactions between GVT members hinders the building of trust which is considered as a crucial factor in forming and maintaining cooperative relationships and effective teamwork (Anderson et al., 2007). Thus, GVT's employment of metadiscourse resources predominantly purports to manage interpersonal relationship among virtual team members through negotiating status distance, creating common ground and managing face so as to build and maintain trust among GVT members.

Most of the influential works that propose metadiscourse classification have centered on written genres (e.g. Kopple, 1985: p. 83; Mauranen, 1993a, 1993b; Hyland, 2005; Adel, 2006; Gillaerts \& Van de Velde, 2010; Adel \& Mauranen, 2010; Kawase, 2015; Hyland \& Jiang, 2016; Carrio-Pastor, 2016). Metadiscourse, though valuable from the perspective of understanding and organizing textual meaning and engaging readers to depict the author's persuasion intention, remains largely unexplored from an interactive viewpoint to study interpersonal interaction function of oral metadiscourse. The latter plays a fundamental role in establishing cooperative relationship in GVT. For example, Liu \& Liu (2017) argue that metapragmatic expressions help achieve mutual understanding in BELF interactions through construct emergent common ground where shared knowledge can be activated and rapport can be created in the communicative process (Kecskes \& Zhang, 2013: p. 340). Walkinshaw et al. (2019) discover that some metadiscourse markers play self-denigration functions to maintain or enhance relational rapport among speakers of BELF by managing face and to promote a sense of in-group solidarity among the participants through generating shared humour.

\subsubsection{Textual Metadiscourse}

Metadiscourse is conceived of in various ways. Highlighting the interpersonal meanings of metadiscourse, Hyland's classification of interactive metadiscourse 
and interactional metadiscourse is mostly acknowledged and applied in recognizing and depicting metadiscourse. However, metadiscursively speaking, previous research has found general differences between speech and writing (e.g. Crystal, 2001: pp. 25-28): typically, speech is part of an interaction between the speaker and audience while writing is the work of the writer who is distant from the reader. A speaker uses more metadiscourse markers in dialogues than in monologues (Zhang, et al., 2017). Conventional taxonomy of metadiscourse (e.g. Hyland, 2005; Adel, 2006; Mauranen, 1993a, 19993b) mainly derives from study of written genres and monologue, may not be capable of describing the metadiscourse profile of GVT where two-way communication is pervasive in communication. Comparing with Hyland's taxonomy, this research inherits Hyland's recognition of interactive metadiscourse (transitions, frame markers, endophoric markers, evidentials, code glosses) and places them in the category of textual metadiscourse which helps the interlocutor to organize discourse and to guide the recipient through the text. Meanwhile, a new sub-type of metadiscourse marker "turn-manipulator" is proposed to this category, which serves the function of initiating, allocating, terminating turns of speech. It differs from "transition" metadiscourse marker in the feature of two-way communication where utterances of different sources rather than different clauses of the same source are linked and manipulated. This research integrates Hyland's interactional metadiscourse into relational metadiscourse introduced in previous section, both of which share the function of establishing engagement and solidarity with interlocutors.

\subsubsection{BELF-Facilitating Metadiscourse}

BELF refers to language used by internationally operating business professionals to communicate with other (mostly) non-native speakers (Kankaanranta \& Louhiala-Salminen, 2013). The proficiency of BELF is no more benchmarking to native speakers but rather to an effective business communicator no matter what his/her native tongue. The correctness of English in use is far less significant than getting the work done and creating rapport-no matter how limited the English proficiency of the users. However, such a competence, albeit modest on the surface level, implies a number of components. BELF speakers need to possess accommodation skills, listening skills, an ability to understand different "Englishes", and overall, tolerance towards different communication styles. In essence, BELF is very different from a "natural" language spoken with native speakers because it is highly situation-specific, dynamic, idiosyncratic and consequently, inherently tolerant of different varieties. The dynamism entails that strategic skills, such as ability to ask for clarifications, make questions, repeat utterances, and paraphrase (see Mauranen, 2006), all of which are mainly achieved through the use of metadiscourse.

Firth $(1996,2009)$ found that "let it pass" and "make it normal" are the two principles observed by effective communicators in the ELF talk, assisted by a diverse employment of discursive devices of reference or repetition. Schegloff 
(2007) emphasizes the function of repair in conversation and defines it as "efforts to deal with trouble-sources or repairables-marked off as distinct within the ongoing talk". Further, he discovers two types of repair-initiation techniques (self-initiated repair and other-initiated repair) and four types of repair sequences (Schegloff et al., 1977). Francis and Hunston (1992: p. 133) detect a prominent act of "reformulate" in BELF communication which functions "to acknowledge a preceding utterance or offer a revised version of it". They position it as a subcategory of repair, considering that repair covers a wide range of remedies of sequences in conversation, whereas to reformulate is specifically to rephrase or revise the term or phrases uttered in a previous turn. Based on Schegloff et al. (1977) analysis of repair, reformulation is classified as four types (Self-initiated self-reformulation, Self-initiated other reformulation, Other-initiated self-reformulation, Other-initiated other-reformulation) (Tsuchiya \& Handford, 2014).

Prior research are unanimous in the common use of metadiscourse to facilitate the intelligibility of BELF users' utterances irrespective of whether the discursive devices that are recognized as metadiscourse by pragmatic academia are phrased as metadiscourse in their research works. In this study, we propose a category-BELF-facilitating metadiscourse to accommodate all the metadiscourse which address difficulties in BELF processing, production and communication by non-native speakers of English in business settings. The recognition and discussion of BELF-facilitating metadiscourse is conducive to further understanding of the metadiscourse features of Internet-mediated BELF communication.

\subsection{The Working Scheme of Three-Dimension Model of Metadiscourse Taxonomy in GVT Internal Communication}

Ayoko et al. (2002) found that $90 \%$ of respondents reported that at least $50 \%$ of conflict among members of diverse teams is due to cultural differences in work orientation and opinions regarding work processes and how people should interact, as well as language differences. This phenomenon is even more severe in GVT, given that GVT communication has three unique contextual attributes: team communication is among multiple cultures; using the non-native language-BELF as work language; using Internet as communication media. They exert a profound influence on discourse production during GVT internal communication in which textual metadiscourse, relational metadiscourse, BELF-facilitating metadiscourse are tactfully employed to perform functions of text coherence, interpersonal relationship establishment and management and facilitation of communication in BELF. The ultimate communicative purposes that are achieved through the use of metadiscourse strategies are improving the accuracy of information transmitted in the team and building up trust among team members.

As is demonstrated in Figure 1, the analytical framework of this study consists of the analysis of contextual attributes, detection of metadiscourse strategies 


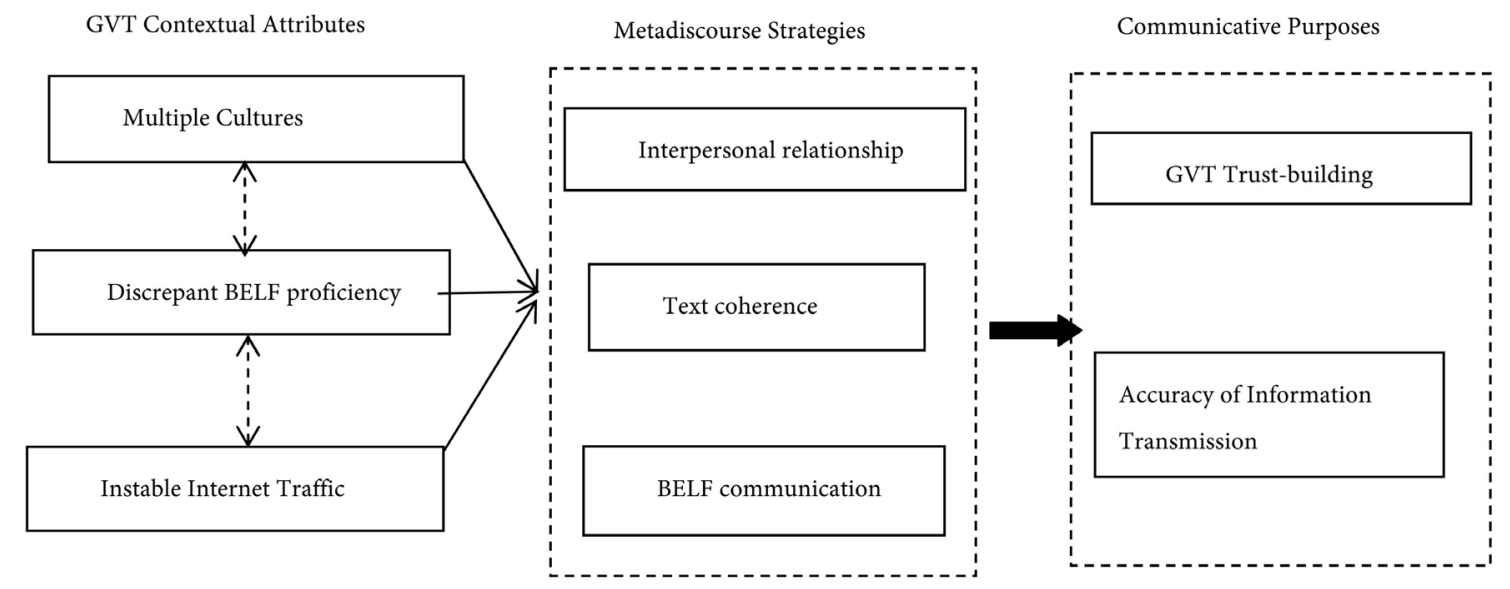

Figure 1. The working scheme of three-dimension model of metadiscourse taxonomy.

in relation to textual, relational, BELF-facilitating resources and the discussion on how the two communicative purposes are realized through metadiscourse strategies. This study identifies textual metadiscourse, relational metadiscourse and BELF-facilitating metadiscourse by tracing metadiscourse markers and observes how they realize functions of textual coherence, interpersonal relationship establishment and management, and facilitation of BELF communication.

\subsection{Summary}

This section builds up a three-dimension model of metadiscourse taxonomy in GVT internal communication which posits that the use of metadiscourse in GVT internal communication is highly subject to the influences of three contextual factors: multiple cultures, discrepant BELF proficiency, instable internet traffic. Therefore, metadiscourse taxonomy can be divided into three dimensions, each corresponding to one contextual factor. Relational metadiscourse helps bridge cultural divides while textual metadiscourse focuses on accuracy information exchange. BELF-facilitating metadiscourse specializes in facilitating the communication of poor BELF speakers. Different from the dominant dichotomy between interactive metadiscourse and interactional metadiscourse, three dimension model of metadiscourse taxonomy considers the integrated impact of the contexts derived from three unique attributes of GVT internal communication. The following sections will give a more detailed elaboration on metadiscourse marker detection and its definition.

\section{Methodology}

\subsection{Research Design}

This study is conducted through three stages. At stage one, based on Hyland (2005)'s enumeration of interactive and interactional metadiscourse markers, this study identifies metadiscourse in the meeting transcript. At stage two, the transcript is examined and annotated manually to add more discourse markers to Hyland's framework. At stage three, this study sorts out all metadiscourse 
markers recognized in stage one and stage two and classify them into groups. At last, this study proposes a three-dimension model of metadiscourse in GVT internal communication with clear definition and examples of each subgroup under main dimensions.

\subsection{Data Collection and Analysis}

Data analysis adopts a deductive approach at the first stage and an inductive approach at the second stage. At stage one, this study uses Antconc3.2 to identify metadiscourse in the meeting transcript and code them for later observation. At stage two, the author and one $\mathrm{PhD}$ student of linguistics read the transcript and manually annotates additional discourse markers that haven't be recognized in Hyland's framework but facilitate GVT's communication, supporting communicators' position, and building interpersonal relationship among GVT members (Hyland, 2004). Prior literature review helps build up three categories of metadiscouse used in GVT. According to the different functions metadiscourse markers performed in the meeting utterances, this study recognizes new metadiscourse markers of relational resource, BELF-facilitating resource from the transcript and depicts the pragmatic functions metadiscourse performs in GVT communication to address the unique challenges brought by GVT internal communication to achieve effective communication. With the consent of the GVT team of a multinational IT company, internal meetings of GVT were recorded. A mini-corpus is established based on the meeting data which comprised 7 audio recorded meetings with circa 427 minutes of talk. The topics cover market development, talent recruitment and knowledge sharing ( 2 meetings about market development, 3 about talent recruitment and 2 about information sharing among GVT members). The recording of the meeting was transcribed according to Jefferson's (1978) transcription system.

\section{Metadiscourse Taxonomy and Pragmatic Functions of GVT Internal Communication}

\subsection{Metadiscourse Taxonomy of GVT Internal Communication}

Based on literature review and corpus analysis, this study identifies 15 metadiscourse categories from three dimensions: textual metadiscourse, relational metadiscourse, BELF-facilitating metadiscourse. The specific classification is as shown in Table 1.

This research proposes three dimensions of metadiscourse according to different functions they play in addressing the difficulties derived from GVT internal communication circumstances. Textual dimension which deals with the coherence of text and the transition of speech turns includes 6 categories of metadiscourse markers: transitions, frame markers, endophoric markers, evidentials, code glosses and turn-manipulator. The prior 4 categories are inherited from Hyland's framework of interactive metadiscourse while the last one is proposed by this study which specializes in initiating, allocating, or terminating turns of 
Table 1. Metadiscourse taxonomy of GVT internal communication.

\begin{tabular}{|c|c|c|}
\hline Textual metadiscourse & Function & Example \\
\hline transitions & $\begin{array}{l}\text { express relations between main } \\
\text { clauses }\end{array}$ & So, but, thus \\
\hline frame markers & $\begin{array}{l}\text { signal discourse acts, sequences } \\
\text { or stages, }\end{array}$ & Firstly, then, lastly \\
\hline endophoric markers & $\begin{array}{l}\text { refer the reader to information in } \\
\text { other parts of the text }\end{array}$ & Before, above, As what you just said \\
\hline evidentials & $\begin{array}{l}\text { refer to information from other } \\
\text { texts }\end{array}$ & According to, She said, Based on \\
\hline code glosses & elaborate propositional meanings & Namely, That's to say, I mean \\
\hline turn-manipulator & $\begin{array}{l}\text { initiate, allocate, or terminate } \\
\text { turns of speech }\end{array}$ & $\begin{array}{l}\text { I stop here, } \\
\text { I'd like to hear XXX's idea, } \\
\text { That's my thought. How about XXX? }\end{array}$ \\
\hline Relational metadiscourse & Function & Example \\
\hline stance marker & clarify speaker's standpoint & $\begin{array}{l}\text { I'm not..., just to ... } \\
\text { But the point is that } \\
\text { personally }\end{array}$ \\
\hline emotion marker & express speaker's emotions & $\begin{array}{l}\text { Come on!, Please! } \\
\text { If I'm very frank to talk about }\end{array}$ \\
\hline status-negotiating marker & $\begin{array}{l}\text { negotiate status distance between } \\
\text { interlocutors }\end{array}$ & $\begin{array}{l}\text { Correct me, if I summarize it in the } \\
\text { wrong way. } \\
\text { If there's anything that you think we } \\
\text { are missing... } \\
\text { I'm not an expert but... }\end{array}$ \\
\hline $\begin{array}{l}\text { common-ground- } \\
\text { generating marker* }\end{array}$ & $\begin{array}{l}\text { help activate shared knowledge, } \\
\text { experience between interlocutors }\end{array}$ & $\begin{array}{l}\text { You know when... } \\
\text { You know we used to... } \\
\text { I remembered we are all in the ... }\end{array}$ \\
\hline BELF-facilitating resource & Function & Example \\
\hline $\begin{array}{l}\text { repetition (Lichtkoppler, } \\
\text { 2007) }\end{array}$ & $\begin{array}{l}\text { fill in broken expressions, } \\
\text { sentences by repeating the prior } \\
\text { words to enable fluent } \\
\text { information flow }\end{array}$ & $\begin{array}{l}\text { in in.in.in.in one interesting sentence, } \\
\text { to..to.be a..a manager } \\
\text { a..a.for..the...for my team }\end{array}$ \\
\hline $\begin{array}{l}\text { self-repair marker } \\
\text { (Lichtkoppler, 2007) }\end{array}$ & $\begin{array}{l}\text { complement additional } \\
\text { information to amend the } \\
\text { previous interpretation }\end{array}$ & $\begin{array}{l}\text { I mean (not as code gloss) } \\
\text { Here is the thing } \\
\text { This is... I think }\end{array}$ \\
\hline $\begin{array}{l}\text { clarification marker } \\
\text { (Lichtkoppler, 2007) }\end{array}$ & confirm information & $\begin{array}{l}\text { having this ... having that... } \\
\text { This is what I mean } \\
\text { I'm saying that }\end{array}$ \\
\hline $\begin{array}{l}\text { reformation marker } \\
\text { (Mauranen, 2006) }\end{array}$ & $\begin{array}{l}\text { signal the change of ways of } \\
\text { information presentation }\end{array}$ & $\begin{array}{l}\text { Forget about that } \\
\text { Ok, I'll put it this way }\end{array}$ \\
\hline $\begin{array}{l}\text { co-construction marker } \\
\text { (Mauranen, 2006) }\end{array}$ & $\begin{array}{l}\text { cooperate with another party in } \\
\text { explaining information }\end{array}$ & $\begin{array}{l}\text { Yeah, I'm with you. } \\
\text { I got what she meant } \\
\text { What she said was }\end{array}$ \\
\hline
\end{tabular}

speech. Relational dimension focuses on management of interpersonal relationship. It includes: stance marker, emotion marker, status-negotiating marker and 
common-ground-generating marker. Stance marker denotes metadiscourse that clarifies speaker's standpoint. Emotion marker refers to metadiscourse that expresses speaker's emotions. Status-negotiating marker is defined as metadiscourse that helps negotiate status distance between interlocutors. Common-ground-generating marker helps activate shared knowledge, experience between interlocutors. BELF-facilitating dimension concentrates on accommodating all the metadiscourse which facilitate the information exchange in BELF processing, production and communication by non-native speakers of English in business settings. This study recognizes 5 categories of BELF-facilitating markers, based on prior research's detection of similar discursive phenomena in their data. They are repetition, self-repair marker, clarification marker (Lichtkoppler, 2007), reformation marker and co-construction marker (Mauranen, 2006). Repetition refers to metadiscourse that fill in broken expressions, sentences by repeating the prior words to enable fluent information flow. Self-repair marker means metadiscourse that provides complementary additional information to amend the previous interpretation. Clarification marker helps to confirm information. Reformation marker refers to metadiscourse that signals the change of ways of information presentation. Co-construction marker refers to metadiscourse that cooperates with another party in explaining information. Each category of metadiscourse serves a unique pragmatic function in GVT internal communication.

\subsection{Pragmatic Functions of GVT Internal Communication}

As for the presence of metadiscourse of GVT communication and its unique pragmatic functions, previous studies have found that metadiscourse is more common in more abstract and informative genres (academic papers, news reviews, etc.) and mainly realize discourse elaboration function. And metadiscourse is seldom used in descriptive and concrete genres (novels and news reports) and is only used to guide readers (Zhang et al., 2017). However, the results of this study show that GVT internal communication massively employs metadiscourse and its pragmatic functions go beyond explaining and organizing text. The interpersonal relationship negotiation and BELF-facilitating are the major functions GVT metadiscourse performs. This finding disagrees with the predominant perception that spoken genres which mainly perform interpersonal communication functions have less information density and adopt more informal styles than written genres, thus should adopt a limited number of metadiscourses.

Trust and knowledge sharing are considered the priority of a GVT's communication. Mutual trust among team members should be cultivated through establishing their harmonious relationship in communication. And knowledge sharing means frequent exchange of insights, attitudes, ideology, new information among team members. Due to the cultural differences, efficiency and accuracy of GVT knowledge sharing is severely affected by team member's cultural and 
ideological divide. The use of relational metadiscourse helps to mediate team members' position, emotion and relative status by which their cultural and ideological cognition is reflected in the utterance, eventually plays a profound role in establishing a harmonious relationship through managing the conflict between individuals' benefit and team's benefits, different perceptions towards power distance and face (mianzi). According to the examination of data, GVT members tend to adapt themselves to the dominant culture when cultures collide. The analysis of data suggests that relational metadiscourse plays a pivotal role in implementing strategy of adapting to the dominant culture of GVT. GVT members employ stance marker and status-negotiating marker to mediate proper position, emotion and relative status of themselves and other colleagues in the team to establish a certain interpersonal relationship in conformity with the dominant cultural norms.

GVT members' proficiency of BELF is discrepant, which means GVT members' uneven performances in BELF processing, production and communication. This study discovers that BELF-facilitating metadiscourse is employed to bridge the gap and improve the intelligibility of different English varieties. The accommodation of non-native speakers' English is realized by BELF-facilitating metadiscourse such as clarification, repetition, co-construction, reformation and self-repair. To be specific, there are three strategic skills. The first skill is to repeat previous morphemes to pronounce an unfamiliar vocabulary correctly. E.g. "Yeah, I will dupli, dupli, e, duplicate this plan...". The second skill is to clarify the information. Usually the metadiscourse marker is used to signal that this is a paraphrase. E.g. "This is what I mean", "I'm saying that". When the utterance cannot convey sufficient information due to BELF deficiency, interlocutors adopt self-repair metadiscourse to complement additional information, e.g. "I mean (not as code gloss)", "Here is the thing", "This is... I think". When the idea is wrongly presented by the language, interlocutors adopt reformation metadiscourse to signal the change of ways of information presentation, e.g.: "Forget about that". "Ok, I'll put it this way". When one person can't express himself clearly, another party may assist him in explaining information by employing the metadiscourse of co-construction, e.g.: "Yeah, I'm with you.", "I got what she meant", "What she said was...". Based on the examination of the mini-corpus of GVT meetings, this study discovers that to cope with the discrepant BELF proficiency and to enhance intelligibility of BELF Speaker's utterance, "repetition", "self-repair" and "co-construction of meaning" are the major metadiscourse categories used in GVT internal communication.

Due to the unstable internet traffic load, information transmission of GVT communication is occasionally delayed and the information flow of utterances is easily disturbed by immediate disconnection of internet signals. Thus, GVT communicators adopt textual metadiscourse more often than co-located team communicators to improve the cohesiveness of the utterance and guide the information recipient to better understand the information and its textual con- 
texts. Among all types of textual metadiscourse markers, turn-manipulator is extensively employed, given that turn exchange is more frequent in dialogues than monologues. Generally, the interlocutor is inclined to employ turn-manipulating metadiscourse to designate turn takers or claim the legitimacy of turn-taking behavior so that the chance of turn collision caused by unstable internet traffic can be avoided. Everyone in the team, geographically dispersed, reaches a consensus in using metadiscourse to initiate, transfer or terminate his own speech so that others can easily follow the information flow within intact contexts by simply paying attention to the turn-manipulator in his speech. The proper use of turn-manipulator guarantees the wholeness of information exchanged among GVT members through busy internet traffic which is conducive to the accuracy of information transmission in GVT internal communication.

\subsection{Summary}

Based on literature review and discourse analysis of a mini corpus of video conferences of a GVT in a multinational IT corporation, this study uses pragmatic analysis to explore how GVT members use metadiscourse strategies to bridge cultural differences, business English as lingua franca (BELF) proficiency gap and Internet-mediated communication barriers to achieve effective communication. This study discovers three dimensions of metadiscourse used in GVT internal communication: relational resources, textual resources and BELF-facilitating resources, proposes a novel framework to classify GVT metadiscourse. By pragmatic analysis of the corpus, it is suggested that to bridge cultural differences, relational metadiscourse plays a pivotal role in implementing strategy of adapting to the dominant culture of GVT. GVT members employ stance marker and status-negotiating marker to mediate proper position, emotion and relative status of themselves and other colleagues in the team to establish a certain interpersonal relationship in conformity with the dominant cultural norms. To cope with BELF competence gap, BELF-facilitating metadisoucrse of "repetition", "self repair" and "co-construction of meaning" are the most commonly used in GVT internal communication. In response to the Internet-mediated communication barriers, textual metadiscourses of "turn-manipulator" manipulate the frequency and length of speech turn to ensure the coherence and accuracy of information transmission. The interlocutor is inclined to employ turn-manipulating metadiscourse to designate turn takers or claim the legitimacy of turn-taking behavior so that the chance of turn collision caused by instable internet traffic can be avoided.

\section{Conclusion}

This study is a preliminary study based on a single case where only one MNC's one GVT's internal communication texts are examined. The three-dimensional framework of metadiscourse classification in GVT internal communication hasn't been proved sophisticated due to the limited number of data at hand. 
However, hopefully this seminal research may draw more attention from academia to the unique characteristics of metadiscourse usage in GVT context. And a series of follow-up research is yet to come so that the proposed GVT metadiscourse framework can be further verified by quantitative research with expanded corpus. Besides, the pragmatic functions of each metadiscourse marker in the GVT context are also worth in-depth investigating for some areas are still unknown. For example, the criteria are still unclear about how to distinguish the use of "I mean" in the textual category of code glosses and BELF-facilitating category of self-repair. Given that BELF-facilitating metadiscourse markers of repetition, self-repair, clarification and reformation's pragmatic functions are achieved by one party's involvement whereas co-construction is realized by other parties' participation, does the number of participants' involvement influence the effects metadiscourse takes in GVT internal communication? These are some of the questions future research can explore.

\section{Conflicts of Interest}

The author declares no conflicts of interest regarding the publication of this paper.

\section{References}

Adel, A. (2006). Metadiscourse in L1 and L2 English. Amsterdam/Philadelphia, PA: John Benjamins Publishing Company. https://doi.org/10.1075/scl.24

Adel, A., \& Mauranen, A. (2010). Metadiscourse: Diverse and Divided Perspectives. Nordic Journal of English Studies, 9, 1-11. https://doi.org/10.35360/njes.215

Alsharo, M., Gregg, D., \& Ramirez, R. (2017). Virtual Team Effectiveness: The Role of Knowledge Sharing and Trust. Information \& Management, 54, 479-490. https://doi.org/10.1016/j.im.2016.10.005

Anderson, A. H., McEwan, R., Bal, J., \& Carletta, J. (2007). Virtual Team Meetings: An Analysis of Communication and Context. Computers in Human Behavior, 23, 2558-2580. https://doi.org/10.1016/j.chb.2007.01.001

Ayoko, O. B., Hartel, C. E. J., \& Callan, V. J. (2002). Resolving the Puzzle of Productive and Destructive Conflict in Culturally Heterogeneous Workgroups: A Communication Accommodation Theory Approach. The International Journal of Conflict Management, 13, 165-195. https://doi.org/10.1108/eb022873

Barinaga, E. (2007). "Cultural Diversity" at Work: "National Culture" as a Discourse Organizing an International Group Project. Human Relations, 60, 315-340. https://doi.org/10.1177/0018726707075883

Blackburn, R. S., Furst, S. A., \& Rosen, B. (2003). Building a Winning Virtual Team. In C. Gibson, \& S. Cohen (Eds.), Virtual Teams That Work: Creating Conditions for Effective virtual Teams (pp. 95-120). San Francisco, CA: Jossey Bass.

Buttny, R. (2010). Citizen Participation, Metadiscourse, and Accountability: A Public Hearing on a Zoning Change for Walmart. Journal of Communication, 60, 636-659. https://doi.org/10.1111/j.1460-2466.2010.01507.x

Carrio-Pastor, M. L. (2016). Technology Implementation in Second Language Teaching and Translation Studies. Singapore: Springer.

https://doi.org/10.1007/978-981-10-0572-5 
Crismore, A., \& Farnsworth, R. (1990). Metadiscourse in Popular and Professional Science Discourse. Writing Scholar. Studies in Academic Discourse. Sage, Newbury Park, CA.

Crystal, D. (2001). Language and the Internet. Cambridge: Cambridge University Press. https://doi.org/10.1017/CBO9781139164771

Doherty Sneddon, G., Anderson, A. H., O’Malley, C., Langton, S., Garrod, S., \& Bruce, V. (1997). Face-to-Face Interaction and Video Mediated Communication: A Comparison of Dialogue Structure and Co-Operative Task Performance. Journal of Experimental Psychology: Applied, 3, 105-125. https://doi.org/10.1037/1076-898X.3.2.105

Firth, A. (1996). The discursive accomplishment of normality: on 'lingua franca' English and conversation analysis. Journal of Pragmatics 26, 237--259.

https://doi.org/10.1016/0378-2166(96)00014-8

Firth, A. (2009). Doing Not Being a Foreign Language Learner: English as A Lingua Franca in the Workplace and (Some) Implications for SLA. International Review of Applied Linguistics in Language Teaching, 47, 127-156. https://doi.org/10.1515/iral.2009.006

Francis, G., \& Hunston, S. (1992). Analysing Everyday Conversation. In M. Coulthard (Ed.), Advances in Spoken Discourse Analysis (pp. 123-161). London: Routledge.

Fujimoto, Y., Bahfen, N., Fermelis, J., \& Hartel, C. E. J. (2007). The Global Village: Online Cross-Cultural Communication and HRM. Cross Cultural Management, 14, 7-22. https://doi.org/10.1108/13527600710718804

García, M. del C. M., \& Cañado, M. L. P. (2011). Multicultural Teamwork as a Source of Experiential Learning and Intercultural Development. Journal of English Studies, No. 9, 143-164. https://doi.org/10.18172/jes.169

Gillaerts, P., \& Van de Velde, F. (2010). Interactional Metadiscourse in Research Article Abstracts. Journal of English for Academic Purposes, 9, 128-139.

https://doi.org/10.1016/j.jeap.2010.02.004

Glazer, S., Kożusznik, M. W., \& Shargo, I. A. (2012). Global Virtual Teams: A Cure for-Or a Cause of-Stress. The Role of the Economic Crisis on Occupational Stress and Well Being, 10, 213-266. https://doi.org/10.1108/S1479-3555(2012)0000010010

Gudykunst, W. B., Matsumoto, Y., Ting-Toomey, S., Nishida, T., Kim, K., \& Heyman, S. (1996). The Influence of Cultural Individualism-Collectivism, Self-Construals, and Individual Values on Communication Styles across Cultures. Human Communication Research, 22, 510-543. https://doi.org/10.1111/j.1468-2958.1996.tb00377.x

Guillem, S. M. (2009). Argumentation, Metadiscourse and Social Cognition: Organizing Knowledge in Political Communication. Discourse \& Society, 20, 727-746. https://doi.org/10.1177/0957926509342368

Hall, E. T. (1976). Beyond Culture. New York: Anchor Press.

Hofstede, G. (1980). Culture and Organizations. International Studies of Management \& Organization, 10, 15-41. https://doi.org/10.1080/00208825.1980.11656300

Hofstede, G. J. (1991). Culture and Organizations: Software of the Mind. London: McGraw-Hill.

Hyland, K. (2004). Disciplinary Interactions: Metadiscourse in L2 Postgraduate Writing. Journal of Second Language Writing, 13, 133-151. https://doi.org/10.1016/j.jslw.2004.02.001

Hyland, K. (2005). Metadiscourse: Exploring Interaction in Writing. London: Continuum.

Hyland, K., \& Jiang, F. (2018). "In This Paper We Suggest”: Changing Patterns of Discip- 
linary Metadiscourse. English for Specific Purposes, 51, 18-30.

https://doi.org/10.1016/j.esp.2018.02.001

Hyland, K., \& Jiang, K. (2016). Change of Attitude? A Diachronic Study of Stance. Written Communication, 33, 251-274. https://doi.org/10.1177/0741088316650399

Jefferson, G. (1978). Sequential Aspects of Storytelling in Conversation. In J. Schenkein (Ed.), Studies in the Organization of Conversational Interaction (pp. 219-248). New York: Academic Press.

Kankaanranta, A., \& Louhiala-Salminen, L. (2013). What Language Does Global Business Speak? The Concept and Development of BELF. Ibérica, 26, 204-209.

Kawase, T. (2015). Metadiscourse in the Introductions of PhD Theses and Research Articles. The Journal of English for Academic Purposes, 20, 114-124.

https://doi.org/10.1016/j.jeap.2015.08.006

Kecskes, I., \& Zhang, F. H. (2013). On the Dynamic Relations between Common Ground and Presupposition. In A. Capone, F. L. Piparo, \& M. Carapezza (Eds.), Perspectives on Linguistic Pragmatics (pp. 375-396). Cham: Springer.

https://doi.org/10.1007/978-3-319-01014-4_15

Kopple, V. (1985). Some Explanatory Discourse on Metadiscourse. College Composition and Communication, 36, 82-93. https://doi.org/10.2307/357609

Li, H. Z. (1999). Communicating Information in Conversations: A Cross-Cultural Comparison. International Journal of Intercultural Relations, 23, 387-409. https://doi.org/10.1016/S0147-1767(99)00003-6

Lichtkoppler, J. (2007). Male. Male._“Male?” —“The Sex Is Male.”-The Role of Repetition in English as a Lingua Franca Conversations. Vienna English Working Papers, 16, 39-65.

Liu, P., \& Liu, H. Y. (2017). Creating Common Ground: The Role of Metapragmatic Expressions in BELF Meeting Interactions. Journal of Pragmatics, 107, 1-15. https://doi.org/10.1016/j.pragma.2016.10.006

Luke, M., \& Gordon, C. (2016). Clinical Supervision via E-Mail: A Review of the Literature and Suggestions for Practice. Using Technology to Enhance Clinical Supervision. American Counseling Association.

Mauranen, A. (1993a). Contrastive ESP Rhetoric: Metatext in Finnish-English Economics Texts. English for Specific Purposes, 12, 3-22.

https://doi.org/10.1016/0889-4906(93)90024-I

Mauranen, A. (1993b). Cultural Differences in Academic Rhetoric: A Text Linguistic Study. Frankfurt am Main: Peter Lang.

Mauranen, A. (2006). Signaling and Preventing Misunderstanding in English as Lingua Franca Communication. International Journal of the Sociology of Language, 177, 123-150. https://doi.org/10.1515/IJSL.2006.008

Nurmi, N. (2011). Coping with Coping Strategies: How Distributed Teams and Their Members Deal with the Stress of Distance, Time Zones and Culture. Stress and Health, 27, 123-143. https://doi.org/10.1002/smi.1327

O’Conail, B., Whittaker, S., \& Wilbur, S. (1993). Conversations over Videoconferences: An Evaluation of Video Mediated Interaction. Human-Computer Interaction, 8 , 382-428. https://doi.org/10.1207/s15327051hci0804_4

Olson, J. S., Olson, G. M., \& Meader, D. K. (1995). What Mix of Video and Audio Is Useful for Remote Real-Time Work? In Proceedings of the Conference of Human Factors in Computing (pp. 33-45). Denver, CO: Academic Press.

https://doi.org/10.1145/223904.223951 
Schegloff, E. (2007). Sequence Organization in Interaction: A Primer in Conversation Analysis. Cambridge: Cambridge University Press. https://doi.org/10.1017/CBO9780511791208

Schegloff, E., Jefferson, G., \& Sacks, H. (1977). The Preference for Self-Correction in the Organization of Repair in Conversation. Language, 53, 361-382. https://doi.org/10.1353/lan.1977.0041

Tang, J., \& Isaacs, E. (1993). Why Do Users Like Video? Studies of Multimedia Supported Collaboration. Computer Supported Collaborative Work: An International Journal, 1, 163-196. https://doi.org/10.1007/BF00752437

Tang, J., Isaacs, E., \& Rua, M. (1994). Supported Distributed Groups with a Montage of Lightweight Interactions. In Proceedings of Computer Supported Collaborative Work 94 (pp. 23-34). New York: ACM. https://doi.org/10.1145/192844.192861

Tenzer, H., Pudelko, M., \& Harzing, A. W. (2014). The Impact of Language Barriers on Trust Formation in Multinational Teams. Journal of International Business Studies, 45, 508-535. https://doi.org/10.1057/jibs.2013.64

Triandis, H. C. (1994). Culture and Social Behavior. New York: McGraw-Hill.

Tsuchiya, K., \& Handford, M. (2014). A Corpus-Driven Analysis of Repair in a Professional ELF Meeting: Not "Letting It Pass". Journal of Pragmatics, 64, 117-131. https://doi.org/10.1016/j.pragma.2014.02.004

Uflacker, M., \& Zeier, A. (2011). A Semantic Network Approach to Analyzing Virtual Team Interactions in the Early Stages of Conceptual Design. Future Generation Computer Systems, 27, 88-99. https://doi.org/10.1016/j.future.2010.05.006

Walkinshaw, I., Mitchell, N., \& Subhan, S. (2019). Self-Denigration as a Relational Strategy in Lingua Franca Talk: Asian English Speakers. Journal of Pragmatics, 139, 40-51. https://doi.org/10.1016/j.pragma.2018.10.013

Zakaria, N. (2017). Emergent Patterns of Switching Behaviors and Intercultural Communication Styles of Global Virtual Teams during Distributed Decision Making. Journal of International Management, 23, 350-366.

https://doi.org/10.1016/j.intman.2016.09.002

Zhang et al. (2017). A Multidimensional Analysis of Metadiscourse Markers across Spoken Registers. Journal of Pragmatics, 117, 106-118.

ttps://doi.org/10.1016/j.pragma.2017.06.004 